Methods 226 male drinkers were enrolled in this study with a standard polysomnography. $\mathrm{ALDH}_{2}$ genotypes were detected by PCR-restriction fragment length polymorphism (PCR-RFLP).

Results (1) We detected three kinds of genotypes and two kinds of allele of ALDH2 gene G1951A polymorphism. The frequency of ALDH2 genotype GG, GA, AA were $0.854,0.137,0.009$ and allele G and A were $0.923,0.077$ respectively in 226 male drinkers.

The genotypic and allelic frequencies were in Hardy-Weinberg equilibrium ( $=0.3606, p=0.5482)$. (2) The frequency of ALDH2 genotype GG/(GA+AA) (0.855/0.145) and allele G/A (0.925/0.075) in OSAHS patients had no statistical differences comparing with the control group ( $p>0.05$. Analysing the data stratified with BMI, there was also no significant differences of the frequency of ALDH2 genotype and allele between OSAHS group and the control group either in normoweight or overweight subjects $(p>0.05)$. (3) There were no any differences in $\mathrm{AHI}$, the lowest $\mathrm{SaO}_{2}$ and the longest apnoea duration between subjects with the two genotypes (GG and $(\mathrm{GA}+\mathrm{AA}))$ either in OSAHS patients or the control group.

Conclusion $\mathrm{ALDH}_{2}$ gene G1951A polymorphism was found in male drinkers, it had no any association with OSAHS.

\section{Q0026 ASSOCIATION BETWEEN THE M235T, T174M POLYMORPHISM OF THE ANGIOTENSINOGEN GENE AND LEFT VENTRICULAR HYPERTROPHY IN ESSENTIAL HYPERTENSION IN KAZAKANS}

doi:10.1136/hrt.2010.208967.26

${ }^{1}$ Zuo Junli, ${ }^{2}$ Li Nanfang, ${ }^{3}$ Zhang Delian, ${ }^{4}$ Zhou Ling, ${ }^{2}$ Li Tao. ${ }^{1}$ Hypertension Unit of The People's Hospital of Xinjiang Uygur Autonomous Region, The Institute of Hypertension of Xinjiang, The Center of Hypertension of The People's Hospital of Xinjiang Uygur Autonomous Region; ${ }^{2}$ Hypertension Unit of The People's Hospital of Xinjiang Uygur Autonomous Region; ${ }^{3}$ The Institute of Hypertension of Xinjiang; ${ }^{4}$ The Center of Hypertension of The People's Hospital of Xinjiang Uygur Autonomous Region

Objective To investigate whether the M235T, T174M polymorphisms of the angiotensinogen gene were associated with left ventricular hypertrophy (LVH) in Xinjiang Kazakans with essential hypertension.

Methods 86 patients with essential hypertension and left ventricular hypertrophy and 95 patients with essential hypertension and nonleft ventricular hypertrophy. Left ventricular hypertrophy was evaluated by the electrocardiography voltage criteria and the Romhilt-Estespoint-score system. The AGT gene M235T, T174M polymorphisms were amplified by PCR and analysed by RFLP.

Results (1) The genotype distributions of the M235T and T174M in both groups were in agreement with Hardy-Weinberg equilibrium. (2) The frequencies of the AGT genotypes and alleles were not significantly different between LVH and NLVH with hypertension. (3) When analysing the frequencies of genotypes and alleles of M235T according to gender ( $p>0.05$ ), no significant differences were found between LVH and NLVH. However, we found a significant difference in frequencies of genotypes and alleles of T174M in NLVH group according to gender.

Conclusion There are no associations between M235T genotype and T174M genotype with the presence of LVH in this study.

\section{e0027 GROWTH DIFFERENTIATION FACTOR 15 INDUCE THE PROLIFERATION OF CARDIAC FIBROBLASTS IN A DOSE DEPENDENT MANNER}

doi:10.1136/hrt.2010.208967.27

Wang Yupeng, Xu Ming, Gao Wei.

Objective Growth differentiation factor 15(GDF-15) is a member of Transforming growth factor- $\beta$ superfamily which is one of the most important profibrotic protein released during Inflammation. It has been suggested that GDF-15 seems to be related to the remodelling processes by anti-hypertrophic in cardiomyocytes. Cardiac fibrosis is one part of the important pathology mechanisms during remodelling. It was still unknown whether GDF-15 could influence remodelling by modulating cardiac fibroblast proliferation and extracellular matrix (ECM) metabolism. Therefore, our study aims to investigate the expression and effects of GDF-15 in the fibroblasts.

Methods Primary myocardial fibroblasts were isolated and cultured from neonatal rats and divided into six groups subjected to different conditions: $10^{-6} \mathrm{~mol} / \mathrm{l}$ Endothelin-1 (ET-1), $10^{-5} \mathrm{~mol} / 1$ norepinephrine (NE), $3 \mathrm{ng} / \mathrm{ml}$ TGF- $\beta 1,5 \mathrm{pg} / \mathrm{ml}$ rhGDF- $15,150 \mathrm{pg} / \mathrm{ml}$ rhGDF-15 and no stimuli. The expression of GDF-15 mRNA was detected by Realtime-PCR and the expression of GDF-15 protein was measured by Enzyme-linked Immunosorbent Assay (ELISA). The proliferation of fibroblast induced by rhGDF-15 was measured by $3-$ (4, 5-dimethylthiazol-2-yl) 2,5-diphenyl tetrazolium bromide (MTT) and Flow cytometry; the migration of fibroblast was shown by Scarification test. The level of phosphor- ERK was determined.

Results GDF-15 is upregulated in ET-1, NE and transforming growth factor (TGF) $\beta 1$ group; the GDF-15 mRNA is respectively $1.21 \pm 0.03$, $1.84 \pm 0.09,1.95 \pm 0.39$ folds of control group (respectively $p<0.05$ $\mathrm{p}<0.05, \mathrm{p}<0.01)$; and protein in the supernatant is respectively $3.27 \pm 0.81 \mathrm{pg} / \mathrm{ml}, \quad 3.55 \pm 0.20 \mathrm{pg} / \mathrm{ml}$ and $3.75 \pm 0.70 \mathrm{pg} / \mathrm{ml}$, vs $0.41 \pm 0.17 \mathrm{pg} / \mathrm{ml}$ of control group (respectively $\mathrm{p}<0.05, \mathrm{p}<0.001$, $\mathrm{p}<0.01)$. rhGDF-15 $(150 \mathrm{pg} / \mathrm{ml})$ increased the OD value as compared to control group $(0.56 \pm 0.03$ vs $0.46 \pm 0.02, \mathrm{p}<0.05)$, but $5 \mathrm{pg} / \mathrm{ml}$ rhGDF-15 did not $(0.43 \pm 0.01$ vs $0.46 \pm 0.02, p>0.05)$. rhGDF-15 $(150 \mathrm{pg} / \mathrm{ml})$ could also raise the cell in $\mathrm{S}$ phase nearly three times more than control group $(9.62 \pm 1.17 \%$ vs $3.80 \pm 0.78 \%, \mathrm{p}<0.01)$. The scarification test showed that rhGDF-15 could enhance the migration of fibroblast. The ERK was activated after treatment with rhGDF-15.

Conclusion GDF-15 is upregulated by ET-1, norepinephrine and TGF- $\beta 1$ in myocardial fibroblasts. rhGDF-15 $(150 \mathrm{pg} / \mathrm{ml})$ could enhance the proliferation and migration of fibroblast, which may participate in the progression of myocardial fibrosis and thus was associated with ERK activation. Abbreviations: Growth differentiation factor 15(GDF-15), Extra cellular matrix (ECM), Endothelin-1(ET-1), norepinephrine (NE), Enzyme-linked Immunosorbent Assay (ELISA), 3-(4,5-dimethylthiazol-2-yl) 2,5-diphenyl tetrazolium bromide (MTT), Transforming growth factor (TGF), Extracellular Signal-Regulated Kinase (ERK).

\section{e0028 THE EFFECT OF ACUTE ACTIVATION OF ALDH2 ON MYOCARDIAL ISCHAEMIA/REPERFUSION INJURY IN RAT}

doi:10.1136/hrt.2010.208967.28

Zhang Fang-Fang, Zhang Fang-Fang, Chen Hong. Department of Cardiology Peking University People's Hospital

Background Our previous study combined several animal experiments conducted recently showed aldehyde dehydrogenase- 2 (ALDH2) was correlated with myocardial ischaemia/infarction injury. But whether ALDH2 is beneficial was controversial. We speculated the way in which the ALDH2 activity was changed may be chiefly responsible for the controversy.

Objective To investigate the effect of acute activation of ALDH2 on myocardial ischaemia/reperfusion injury in rat.

Methods 20 male Sprague-Dawley rats were divided into five groups:sham group $(n=3)$; control group $(n=4)$ :occlusion of the left anterior descending coronary artery $(30 \mathrm{~min})$ followed by reperfusion (15 min); ethanol group $(n=5)$ :intraperitoneal injection of ethanol $(0.5 \mathrm{~g} / \mathrm{kg}) 60 \mathrm{~min}$ prior to ischaemia; GTN-ON group $(\mathrm{n}=3): 18 \mathrm{~h}$ persistent nitroglycerin treatment $(0.1 \mathrm{mg} / \mathrm{h}$, delivered by a patch) combined with intraperitoneal injection of ethanol $(0.5 \mathrm{~g} / \mathrm{kg}) 60 \mathrm{~min}$ prior to ischaemia; GTN-OFF group $(\mathrm{n}=5)$ : 